MEDIALOG: Jurnal IImu Komunikasi, Volume III, No. II, Agustus $2020 \mathrm{hlm} \mathrm{1-12}$

\title{
STRATEGI KOMUNIKASI PT SEMEN INDONESIA (PERSERO) TBK DALAM MANAJEMEN ISU PEMBANGUNAN PABRIK SEMEN DI REMBANG
}

\author{
Sigit Wahono ${ }^{1}$ \\ London School of Public Relations Communication \& Business Institute \\ Email: sgwahono84@gmail.com
}

\begin{abstract}
ABSTRAK
Studi ini bertujuan untuk mengidentifikasi dan menganalisis strategi komunikasi yang dilakukan oleh PT Semen Indonesia (Persero) dalam manajemen isu pembangunan pabrik semen di Rembang menggunakan metode penelitian kualitatif deskriptif. Berdasarkan hasil penelitian, Semen Indonesia telah melakukan upaya pengelolaan isu secara aktif dengan melakukan media monitoring setiap hari untuk memantau perkembangan pemberitaan dan informasi yang beredar di media massa baik cetak maupun online. Pemantauan isu juga dilakukan dengan mengamati opini publik di media sosial maupun berbagai forum diskusi online lainnya. Selanjutnya, Semen Indonesia telah menyusun strategi komunikasi dalam pengelolaan isu pembangunan pabrik semen di Rembang yang dibagi dalam beberapa elemen, meliputi pesan yang disampaikan, pemetaan sasaran komunikasi, media komunikasi yang digunakan, dan melakukan evaluasi terhadap dampak yang diperoleh dari strategi komunikasi yang telah dilakukan. Strategi komunikasi telah diimplementasikan sesuai dengan jadwal yang direncanakan. Dalam melakukan pengelolaan isu, Semen Indonesia melakukan penyampaian informasi yang sesuai antara data dan fakta yang ada. Untuk menjangkau seluruh pemangku kepentingan yang lebih luas, Semen Indonesia menggunakan berbagai media komunikasi yang ada. Perusahaan juga melakukan evaluasi secara periodik untuk mengetahui efektifitas strategi komunikasi yang dilakukan. Selain berdasarkan monitoring isu di media massa dan media sosial, penyesuaian strategi dilakukan dengan menganalisa perkembangan aksi dan agenda setting yang dilakukan oleh pihak kontra.
\end{abstract}

Kata Kunci: Strategi Komunikasi; Manajemen Isu; Pabrik Rembang;

\section{COMMUNICATION STRATEGY OF PT SEMEN INDONESIA (PERSERO) TBK FOR ISSUE MANAGEMENT OF REMBANG CEMENT PLANT}

\begin{abstract}
This study aims to identify, analyze, and determine the factors that influence the success of the communication strategy undertaken by PT Semen Indonesia (Persero)Tbk in the issue management of the cement plant construction in Rembang used descriptive qualitative research methods with case studies. Based on the results of the research, Semen Indonesia has made efforts to actively manage the issue by conducting media monitoring every day to monitor the development of news and information circulating in the print and online mass media. Issue monitoring is also carried out by observing public opinion on social media and various other online discussion forums. Furthermore, Semen Indonesia has compiled a communication strategy in managing the issue of cement factory construction in Rembang which is divided into several elements, including messages delivered, mapping of communication targets, communication media used, and evaluating the impacts obtained from the communication strategies that have been carried out. The communication strategy has been implemented in accordance with the planned schedule. In carrying out the management of the issue, Semen Indonesia carried out the appropriate information between the data and the available facts. To reach all broader stakeholders, Semen Indonesia uses a variety of existing communication media. The company also conducts periodic evaluations to determine the effectiveness of the communication strategy undertaken. In addition to monitoring issues based on mass media and social media, strategy adjustments are made by analyzing the development of actions and agenda settings carried out by counter parties.
\end{abstract}

Keywords: Communication Strategy;, Issue Management; Rembang Plant; 
Korespondensi: Sigit Wahono, ST., MM. London School of Public Relations. Sudirman Park Campus, Jl. Jend. Sudirman No.Kav. 32, RT.12/RW.11, Karet Tengsin, Kota Jakarta Pusat, Daerah Khusus Ibukota Jakarta 10250.

No. HP, WhatsApp: 08113081856. Email: sgwhono84@gmail.com

\section{PENDAHULUAN}

Manajemen isu adalah sebuah alat yang dapat digunakan oleh perusahaan untuk mengidentifikasi, menganalisa dan mengelola berbagai isu yang muncul dalam suatu masyarakat, serta bereaksi terhadap berbagai isu tersebut sebelum diketahui oleh masyarakat luas (Chase dalam Regester \& Larkin, 2002, p.202).

Manajemen isu memiliki hubungan timbal balik dengan manajemen krisis karena suatu isu dapat menciptakan krisis atau krisis dapat menimbulkan isu. Manajemen isu yang efektif adalah bentuk pencegahan krisis. Dengan mengelola isu yang baru lahir, organisasi dapat mengambil tindakan sebelum masalah berkembang menjadi krisis (Coombs \& Holladay, 2010, p.55).

Manajemen isu sebagai instrumen vital bagi masa depan perusahaan berkaitan dengan strategi komunikasi yang digunakan. Perusahaan dapat mengubah pandangan publik dan kebijakan pemangku kepentingan karena memberikan berbagai alasan yang masuk akal dalam menjustifikasi posisi yang mereka sarankan (Heath \& Coombs, 2006, p.269).

Dalam penerapan strategi komunikasi dalam penanganan suatu isu, cakupan liputan media dalam hal jumlah, konten, bahasa, serta penempatan halaman dalam suatu artikel akan berkorelasi dengan persepsi publik (Cockerill, 2002).

Oleh karena itu, manajemen puncak harus menciptakan keunggulan kompetitif berkelanjutan bagi perusahaan dengan penyesuaian dan revisi strategi perusahaan secara tepat waktu. Perusahaan harus memperluas pengetahuan tentang alokasi perhatian dengan menunjukkan bagaimana struktur perhatian pada berbagai tingkat organisasi.

Manajemen isu perlu menjadi bagian dari kebijakan manajemen strategis dalam membantu peningkatan kinerja perusahaan karena kemampuannya memindai, mengidentifikasi dan memonitor isu yang muncul, serta menentukan pemangku kepentingan yang terlibat dalam isu tersebut. Data yang terkumpul dapat membantu penyusunan strategi yang dikembangkan oleh perusahaan sehingga lebih tepat sasaran.

Sementara itu, dari sudut pandang komunikasi massa, manajemen isu berkaitan dengan kegiatan public relations dan propaganda. Kedua kegiatan tersebut memiliki banyak kesamaan dalam upaya menyampaikan informasi kepada target audience. Perbedaan public relations dan propaganda adalah kualitas informasi dan cara penggunaannya.

Propaganda adalah pengelolaan sikap kolektif dengan manipulasi simbol-simbol yang signifikan. Perilaku menunjukkan kecenderungan untuk bertindak sesuai dengan pola penilaian tertentu. Keberadaan suatu perilaku bukanlah suatu pengalaman langsung, tetapi suatu kesimpulan dari tanda-tanda yang memiliki makna konvensi. (Laswell dalam Rogers, 1997, pp. 213-214),

Dalam penelitiannya, Lasswell (1948) telah mengembangkan model komunikasi $5 \mathrm{~W}$ yang berfokus pada "Who (says) What (to) Whom (in) 
Which Channel (with) What Effect". Model komunikasi Lasswell membagi proses komunikasi menjadi lima bagian, meliputi komunikator, informasi, media, khalayak dan efek. Lima bidang penelitian tersebut memberikan sudut pandang yang sangat baik untuk mempelajari komunikasi dengan media baru.

PT Semen Indonesia (Persero) Tbk merupakan salah satu produsen semen ternama di Indonesia dan kawasan regional. Sebagai perusahaan yang berhubungan dengan kepentingan masyarakat, perusahaan secara konsisten terus berupaya untuk memberikan manfaat bagi kesejahteraan masyarakat dan lingkungan sekitarnya, terutama untuk menghindari isu-isu yang terkait dengan dampak negatif yang timbul akibat kegiatan operasional perusahaan.

Dalam pengembangan bisnisnya, PT Semen Indonesia (Persero) Tbk melakukan ekspansi dengan membangun pabrik semen baru di Kabupaten Rembang, Jawa Tengah. Akan tetapi, pembangunan pabrik ini mendapat penolakan dari elemen masyarakat yang mengatasnamakan Jaringan Masyarakat Peduli Pegunungan Kendeng (JMPPK). Penolakan telah dilakukan sejak tahap awal pembangunan pabrik pada tahun 2012 .

Isu Pabrik Rembang semakin membesar ketika prosesi peletakan batu pertama pada tanggal 16 Juni 2014, dimana aksi penentangan beberapa elemen masyarakat Rembang ini mulai diberitakan oleh media massa. Fenomena ini diperkuat dengan adanya pembangunan tenda perjuangan di depan lokasi proyek yang dihuni oleh warga yang menolak pembangunan pabrik (Tempo.co,
Beberapa aksi terus dilakukan oleh kelompok kontra dalam melakukan kampanye dan menggalang dukungan. Salah satunya dengan tindakan persuasi kepada masyarakat tentang potensi kerusakan ekologi yang dihasilkan oleh pabrik semen. Pihak kontra mengkampanyekan bagaimana pentingnya karst dan menyatakan bahwa kawasan penambangan pabrik semen berada di Cekungan Ait Tanah (CAT) Watuputih yang merupakan kawasan lindung geologi.

Dalam perkembangannya, pihak kontra pembangunan pabrik semen melalui Wahana Lingkungan Hidup (Walhi) dan Joko Prianto (tokoh kontra) mengajukan gugatan hukum atas rencana pembangunan pabrik Semen Indonesia pada tanggal 1 September 2014.

Pihak kontra melayangkan gugatan melalui Pengadilan Tata Usaha Negara (PTUN) Semarang untuk mencabut surat keputusan Gubernur Jawa Tengah Nomor 660.1/17 Tahun 2012 pada Juni 2012 tentang izin penambangan PT Semen Gresik (Persero) Tbk, kini PT Semen Indonesia (Persero) Tbk, di Kabupaten Rembang (Tempo.co, Semarang, Senin, 1 September 2014 12:54 WIB).

Isu pembangunan pabrik Semen Indonesia di Rembang memasuki tahap baru ketika sembilan wanita petani yang mengaku mewakili warga Pegunungan Kendeng berunjuk rasa di depan Istana Negara pada tanggal 12 April 2016 dengan menyemen kaki mereka. Mereka menuntut untuk bertemu dengan Presiden Joko Widodo agar dapat menyelesaikan permasalahan pembangunan pabrik semen di Kendeng (BBC Indonesia, Semarang, Rabu, 13 April 2016 13.00 WIB).

Semarang, Kamis, 3 November 2016 19:41 WIB). 
Pada perkembangannya, kegagalan dalam pengelolaan isu Pabrik Rembang menjadi salah satu pendorong Mahkamah Agung (MA) dalam memutuskan kemenangan gugatan warga melalui putusan Peninjauan Kembali (PK). Dalam salinan keputusannya, pertimbangan MA dalam memenangkan PK pihak kontra adalah karena AMDAL Pabrik Rembang-PT Semen Indonesia (Persero) Tbk dinyatakan cacat prosedur. Putusan PK ini sekaligus membatalkan izin lingkungan pembangunan Pabrik Rembang.

Semen Indonesia memiliki bentuk strategi komunikasi yang menarik dan luas dalam manajemen isu pembangunan pabrik semen di Rembang. Perusahaan menghadapi potensi munculnya isu terkait dengan aktivitas produksi dan penambangan, pengurangan lahan pertanian, bencana kekeringan, dan kerusakan lingkungan.

Penerapan Manajemen isu sebagai suatu alat pengelolaan rencana strategis yang efektif dilakukan melalui tahapan identifikasi, analisis, probabilitas, dan proyeksi masalah yang muncul, baik dari lingkungan eksternal maupun internal. Semen Indonesia pada awalnya bersikap pasif dalam menghadapi penolakan sebagian kecil warga. Perusahaan mulai fokus menyusun strategi komunikasi dalam pengelolaan isu ketika fenomena penolakan menjadi pemberitaan yang muncul di berbagai media massa sehingga mempengaruhi citra dan reputasi perusahaan.

\section{METODE PENELITIAN}

\section{A. Jenis Penelitian}

Dalam penelitian ini, peneliti menggunakan metode penelitian kualitatif deskriptif dengan studi kasus. Peneliti memilih metode tersebut untuk mendeskripsikan secara detail bagaimana strategi komunikasi Semen Indonesia dalam manajemen isu dengan studi kasus pembangunan pabrik semen di Rembang.

Menurut Denscombe (dalam Pembayun, 2013, pp.248-249) studi kasus memiliki karakteristik sebagai berikut:

1. Menyoroti suatu peristiwa

2. Penelaahan mendalam

3. Fokus pada hubungan antar aspek kasus dan proses

\section{Setting ilmiah}

5. Penggunaan beberapa sumber dan metode

Alasan peneliti memilih studi kasus dalam penelitian ini adalah dapat memahami suatu peristiwa secara mendalam sehingga dapat memberikan hasil penelitian yang terfokus. Peristiwa yang sedang terjadi di pahami berdasarkan pemahaman peneliti melalui proses dari kasus tersebut.

\section{B. Fokus Penelitian}

Peneliti berfokus pada strategi komunikasi Semen Indonesia dalam proses manajemen isu terkait pembangunan pabrik semen di Rembang. Peneliti mencoba memahami strategi komunikasi yang dilakukan oleh Semen Indonesia secara mendalam.

Tabel 1 Fokus Penelitian

\section{Dimensi} Evidensi 


\begin{tabular}{|l|c|}
\hline $\begin{array}{l}\text { 1. Komunikator } \\
\text { (Who Says) }\end{array}$ & $\begin{array}{c}\text { 1. Juru bicara Semen } \\
\text { Indonesia dalam }\end{array}$ \\
2. Pesan & pengelolaan isu \\
Komunikasi & Pabrik Rembang \\
(Says What \& & 2. Pesan yang \\
How) & disampaikan oleh \\
3. Sasaran & Semen Indonesia \\
Komunikasi (to & 3. Media komunikasi \\
Whom) & yang digunakan oleh \\
4. Media & Semen Indonesia \\
Komunikasi (In & 4. Pemangku \\
Which Channel) & kepentingan yang \\
5. Dampak & menjadi sasaran \\
Komunikasi & komunikasi \\
(What Effect) & 5. Identifikasi dampak \\
& komunikasi yang \\
& telah dilakukan \\
\hline
\end{tabular}

Semen Indonesia sebagai komunikator telah menetapkan strategi komunikasi dalam pengelolaan isu pembangunan pabrik semen di Rembang. Melalui stategi komunikasi inilah, banyak perubahan dalam opini publik mengenai isu pembangunan pabrik semen di Rembang. Peneliti juga ingin mengetahui seberapa besar keberhasilan strategi komunikasi yang telah dilakukan dalam penanganan isu pembangunan pabrik semen di Rembang.

\section{Prosedur Pengumpulan Data}

Dalam penelitian ini, jenis data yang digunakan adalah data primer dan data sekunder. Data primer diperoleh melalui observasi secara langsung dan wawancara secara mendalam, sedangkan data sekunder diperoleh melalui studi pustaka. Data yang terkumpul dipelajari sebagai suatu keseluruhan yang terintegrasi.

Teknik pengumpulan data yang digunakan adalah :

a. Observasi yaitu dengan melakukan pengamatan langsung kepada objek yang sedang diteliti dan senantiasa bersifat objektif faktual atau yang sebenarnya menggambarkan keadaan objek penelitian.

b. Wawancara yaitu dengan melakukan pengumpulan data melalui tanya jawab mendalam secara lisan dan tulisan kepada informan yang diteliti.

c. Studi kepustakaan, yaitu dengan melakukan pengumpulan data melalui membaca dan mempelajari beberapa literatur, materi-materi, laporan hasil penelitian, jurnal-jurnal, dan sebagainya yang memiliki relevansi dengan masalah yang diteliti.

\section{Prosedur Analisis Data}

Menurut Maleong (dalam Kriyantono, 2012, p.167) analisis data didefinisikan sebagai proses yang dikelompokan atau diorganisasikan kemudian data diurutkan dalam suatu pola, kategori atau satuan uraian mendasar sehingga pengelompokan tersebut dapat dirumuskan. Analisis data pada penelitian kualitatif tidak berupa angka-angka melainkan kalimat dan gambar-gambar.

Dalam penelitian ini, proses reduksi data (data reduction) adalah ketika informasi yang diperoleh peneliti dari kajian pustaka dipilih-pilih data dan fakta yang lebih mendekati permasalahan dan diambil intinya. Selanjutnya data yang dipilih ditampilkan dalam bentuk gambar dan teks sehingga memberikan pemahaman dalam 
menganalisis permasalahan pada penelitian. Oleh itu dapat disimpulkan bahwa bukti-bukti yang didapat berupa wawancara, studi kasus dan pengamatan.

\section{E. Teknik Pemeriksaan Kepercayaan}

Dalam penelitian ini, proses pemeriksaan kepercayaan dilakukan dengan pengecekan, pelengkapan, dan verifikasi informasi dengan menggunakan banyak informasi. Menurut Kriyantono (2012, p.71-73), pada penelitian kualitatif proses ini terjadi pada saat proses pengumpulan data dan analisis-interpretasi data.

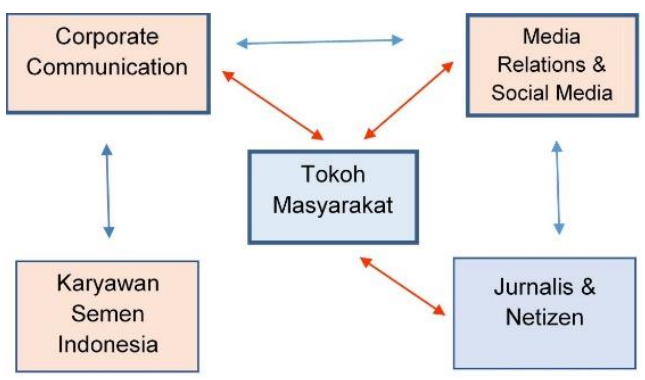

Gambar1. Teknik Trusworthiness

Dalam penelitian ini, teknik trustworthiness triangulasi sumber dilakukan terhadap data yang diperoleh dari empat informan sebagai narasumber internal dari Semen Indonesia dan tiga informan sebagai narasumber eksternal.

\section{HASIL DAN PEMBAHASAN}

Menurut Chase (dalam Kriyantono, 2015, pp.149-150), isu merupakan suatu masalah yang belum terselesaikan dan perlu penanganan cepat untuk mengatasinya.

Aksi penolakan terhadap keberadaan pabrik Semen Indonesia di Rembang memunculkan isu bahwa warga tidak mendapatkan sosialisasi ataupun informasi mengenai pembangunan pabrik semen. Sebagai BUMN, Semen Indonesia telah melakukan seluruh proses perijinan sesuai dengan ketentuan hukum yang belaku. Perusahaan juga telah memenuhi persyaratan AMDAL, yang mewajibkan adanya sosialisasi terhadap warga.

Menurut pihak kontra, penolakan sudah dilakukan sejak awal tetapi tak mendapatkan tanggapan. Mereka menyatakan bahwa dampak sosial dan ekologis pembangunan pabrik semen di Rembang hendaknya menjadi perhatian serius dalam menetapkan persyaratan dokumen AMDAL sebelum izin keluar (Mongabay.co.id, Rembang, Jumat, 8 August 201412.00 WIB).

Anggapan bahwa tidak adanya sosialisasi yang sesuai prosedur dibantah oleh Semen Indonesia yang menyampaikan bahwa sosialisasi sudah dilaksanakan kepada warga sekitar melalui pertunjukan wayang kulit.

\section{Strategi Komunikasi}

Semen Indonesia melakukan pemetaan atas isu-isu yang dihadapi dan membagi ke dalam beberapa kelompok. Perusahaan juga memetakan pemangku kepentingan yang terlibat, khususnya dalam pembentukan opini dan penggalangan dukungan terhadap penolakan tersebut.

Menurut Freeman dalam (Mitchell, Agle \& Wood, 1997), pemangku kepentingan (stakeholder) didefinisikan sebagai setiap kelompok atau individu yang dapat mempengaruhi atau dipengaruhi oleh pencapaian tujuan organisasi atau perusahaan.

Semen Indonesia telah mengidentifikasi dan memonitor perkembangan isu yang muncul dan pemangku kepentingan yang terlibat di dalam isu. 


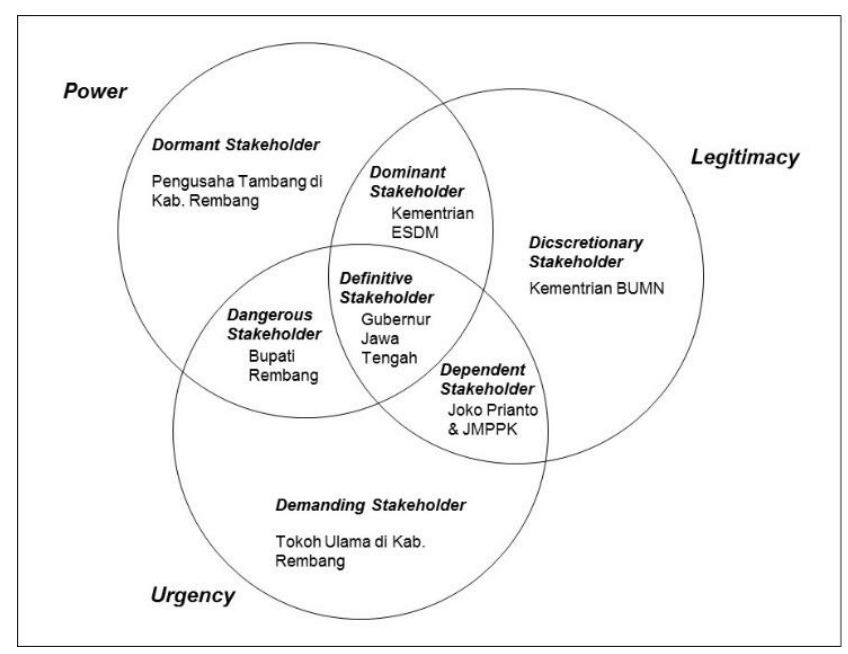

Gambar 2. Peta Pemangku Kepentingan

Semen Indonesia telah melakukan komunikasi dengan para pemangku kepentingan untuk memberikan informasi dan edukasi terkait pabrik semen di Rembang. Pada awal munculnya isu dan konflik, Semen Indonesia tidak terlalu menanggapi kampanye atau pembentukan opini yang dilakukan pihak kontrak. Perusahaan lebih fokus dalam memberikan informasi terkait dengan rencana pembangunan pabrik semen sesuai dengan program komunikasi yang ditetapkan.

Dalam menghadapi pemberitaan media massa dan opini publik di media sosial yang sebagian besar negatif, Semen Indonesia mengambil dua langkah utama. Pertama, perusahaan secara aktif melakukan pembentukan opini positif melalui penyebaran konten pemberdayaan masyarakat rembang dan pengelolaan lingkungan di fasilitas produksinya yang lain. Strategi kedua, perusahaan mendorong berbagai pihak untuk menyebarkan fakta positif untuk menekan rumor yang disebarkan oleh pihak kontra, khususnya di media sosial.

Pada tahap awal, Semen Indonesia mengambil langkah-langkah untuk menyusun rencana pencegahan agar isu tidak berkembang menjadi krisis. Perusahaan memonitor setiap perkembangan isu dan setiap dinamika yang kemungkinan dapat menjadi isu baru yang potensial. Identifikasi terhadap seluruh isu perlu dilakukan untuk menyusun perencanaan dan tindakan yang tepat.

Untuk menyelaraskan rencana penanganan isu dengan rencana strategis perusahaan, Biro Komunikasi Perusahaan mendapatkan arahan dan bimbingan dari managemen puncak. Selain itu, tim komunikasi juga melakukan konsultansi dan mendengarkan masukan dari beberapa ahli dan pakar yang berpengalaman.

Dalam perkembangan isu, berbagai pemberitaan negatif tentang Pabrik Rembang semakin banyak dan didominasi oleh isu lingkungan, salah satunya mengenai manipulasi dalam dokumen AMDAL. Isu mengenai manipulasi dokumen AMDAL disajikan dalam bentuk infografis sehingga lebih mudah dalam mempengaruhi opini publik.

Menurut Nova (2014, p.9), environmental issue adalah isu-isu sensitif tentang lingkungan yang dilakukan oleh perusahaan dengan mengabaikan aturan yang berlaku. Ketidakpedulian terhadap lingkungan dan masyarakat sekitar, serta hanya peduli pada keuntungan (laba) adalah tudingan yang kerap membuat perusahaan tidak berdaya menghadapi tekanan dengan isu lingkungan ini.

\section{Pengelolaan Media Massa \& Media Sosial}

Media massa berpengaruh besar dalam perkembangan isu pembangunan pabrik semen di Rembang. Sejak awal, isu pabrik semen di Rembang muncul dalam berbagai pemberitaan media massa, baik cetak, online, maupun 
elektronik. Konflik dalam pembangunan pabrik semen ini tidak hanya mendapatkan perhatian dari media lokal dan nasional, namun juga muncul dalam pemberitaan media internasional.

Menghadapi media massa yang cenderung negatif, Semen Indonesia membentuk tim media monitoring untuk melakukan pemantauan pemberitaan nasional maupun lokal. Menurut Kriyantono (2015, p.182), monitoring pemberitaan merupakan komponen penting untuk mengetahui sebarapa dalam isu yang berkembang dan strategi apa yang akan dilanjutkan setelahnya.

Proses monitoring dilakukan setiap hari, setiap ada pemberitaan dengan mengamati isi berita dan coverage-nya. Hasil monitoring harian akan digunakan untuk menyusun laporan isu mingguan. Tim media monitoring Semen Indonesia memiliki laporan isu secara formal setiap minggu..

Setiap pemberitaan media massa tentang pabrik semen merupakan sumber informasi yang akan mempengaruhi opini publik serta strategi pengelolaan isu perusahaan. Melalui agenda setting, Semen Indonesia mengemukakan pendapat dari berbagai pemangku kepentingan yang mendukung pembangunan pabrik semen di Rembang. Melalui testimoni dari berbagai pemangku kepentingan yang merasakan langsung dampak positif dari pembangunan pabrik semen, perusahaan ingin memberikan informasi yang menunjukkan bahwa isu dan rumor negatif adalah tidak benar. Langkah publikasi ini dilakukan tanpa menyebutkan isu dan rumor negatif untuk menghindari penyebaran yang lebih luas.

Semen Indonesia juga memberikan akses terbuka bagi institusi, masyarakat maupun media yang ingin melakukan kunjungan. Dalam komunikasi melalui media, salah satu yang penting untuk diperhatikan adalah apa yang dikatakan dan bagaimana mengatakan. Pertemuan dengan media membutuhkan desain yang cemat, mengingat media dapat mengambil posisi untuk memberikan penilaian yang cenderung menekan. Namun, perusahaan yang menyadari bahwa media sangatlah penting dan vital akan menilai bahwa pendekatan dengan media menjadi sangat mutlak untuk dilakukan (Fink, 2000, p.116).

Berbeda dengan media tradisional, media sosial dibangun di atas interaksi dua arah, memungkinkan pengguna untuk berpartisipasi secara aktif, membuat jaringan, serta berbagi informasi dan perspektif satu sama lain. Media sosial semakin dianggap oleh pengguna sebagai sumber data dan pengetahuan yang lebih terpercaya daripada publisitas tradisional seperti periklanan dan televisi (Foux, 2006).

Untuk mengadapi penyebaran konten dan isu negatif melalui media sosial, perusahaan membentuk tim khusus yang menangani pengelolaan akun resmi perusahaan. Pembentukan tim bertujuan untuk mengatur penyebaran pesanpesan melalui media sosial sebagai perimbangan informasi dari pihak Kontra.

Setelah membentuk tim media sosial, Semen Indonesia menyusun konten media sosial mengenai Proyek Rembang pada akun resmi perusahaan. Konten yang disusun sifatnya tidak agresif dengan fokus pada penyampaian progress pembangunan pabrik dan pengelolaan lingkungan dan sosial.

Selain itu, konten lain yang dibuat oleh tim media sosial Semen Indonesia antara lain berisi 
dukungan terhadap Ganjar Pranowo sebagai stakeholder utama, isu nasionalisme untuk mendukung Semen Indonesia sebagai BUMN, dukungan tokoh masyarakat dan warga di sekitar Pabrik Rembang, dan berbagai program pengembangan masyarakat di area operasional Semen Indonesia yang lain.

Konten media sosial, terutama twitter juga digunakan untuk memperluas berita positif tentang Semen Indonesia dan Pabrik Rembang yang dimuat oleh media online. Media massa mulai tertarik dengan fakta yang menunjukkan banyaknya dukungan masyarakat Rembang terhadap pembangunan pabrik semen.

Pemberitaan di media massa dan berbagai konten media sosial yang dimuat di akun resmi perusahaan mulai menghasilkan pemahaman masyarakat bahwa Semen Indonesia didukung oleh sebagian besar warga ring satu. Publik mulai melihat dukungan dari berbagai cuitan, postingan serta komentar-komentar yang diberikan oleh warga Rembang.

\section{Pemulihan Citra dan Reputasi}

Benoit (1995) mendefinisikan citra sebagai persepsi tentang perusahaan dalam benak publik yang dibentuk oleh kata-kata dan perilaku perusahaan tersebut, serta oleh tindakan pihak lain yang relevan. Ketika tindakan perusahaan diamati secara ketat, perusahaan perlu memahami perilaku yang dapat diterima oleh publik dan mengatur perilakunya untuk mempertahankan citra positif perusahaan.
Ketika citra perusahaan rusak karena beberapa hal, perusahaan harus mengambil langkah-langkah yang diperlukan untuk memperbaikinya. Berdasarkan Benoit (1995), tipologi strategi perbaikan citra dan reputasi dikelompokkan ke dalam lima kategori, yaitu, penyangkalan (denial), menghindari tanggung jawab (evasion of responsibility), mengurangi pelanggaran (reduction of offensiveness), tindakan korektif (corrective action), serta pengakuan dan permohonan maaf (mortification).

Pada awalnya, kegagalan Semen Indonesia dalam menangani isu negatif secara cepat mendatangkan isu negatif lainnya. Penyampaian Informasi yang kurang terencana terkait perkembangan proyek pabrik semen di Rembang mengakibatkan masyarakat berspekulasi negatif sehingga mengancam citra Semen Indonesia.

Salah satu langkah yang dilakukan oleh Semen Indonesia dalam mengelola citra terkait isu negatif Pabrik Rembang adalah perusahaan berusaha untuk mengurangi tingkat dampak yang dialami oleh pemangku kepentingan. Selain menyeimbangan isu lingkungan, perusahan juga mengkampanyekan mengenai dampak positif di bidang ekonomi dengan adanya pabrik semen di Rembang.

Langkah lain yang dilakukan oleh Semen Indonesia dalam menjaga citra dan reputasi adalah dengan strategi Bolstering atau melibatkan proses membangun karakter perusahaan untuk menunjukkan kualitas positif kepada publik. Langkah ini secara efektif mampu mengimbangi pandangan negatif publik, terutama jika citra secara langsung bertentangan dengan tindakan yang bersangkutan (Benoit, 1995, pp.24-27). 
Selain itu, perusahaan juga melakukan berbagai strategi Minimization dengan mengurangi dampak negatif dimana publik akan berasosiasi dengan tindakan tersebut. Langkah ini dilakukan dengan melakukan berbagai program yang dapat memberikan dampak positif secara langsung kepada masyarakat sekitar. Salah satu contoh program yang dilakukan oleh Semen Indonesia dalam menjawab kekhawatiran masyarakat mengenai sumber air adalah dengan pembangunan embung.

Meskipun belum berproduksi, Semen Indonesia telah memahami kegelisahan para petani di Rembang. Selain berbagai program sosial, perusahan turut mendukung sektor pertanian dengan membangun embung untuk pengairan lahan masyarakat.

Pada tahun 2017, Semen Indonesia melakukan pembangunan embung yang digunakan untuk memenuhi kebutuhan air bagi ratusan hektare sawah sehingga dapat berproduksi maksimal tanpa harus menunggu musim hujan. Meskipun belum melakukan kegiatan penambangan, Semen Indonesia telah membuktikan tujuan menyejahterakan masyarakat sejak dini dengan membangun embung air untuk warga (Mediaindonesia.com, Jakarta, Minggu, 7 Mei 2017 14:49 WIB).

\section{SIMPULAN}

Berdasarkan hasil analisis, peneliti menyimpulkan bahwa Semen Indonesia telah melakukan upaya pengelolaan isu secara aktif. Proses manajemen isu dilakukan dengan melakukan media monitoring setiap hari untuk memantau perkembangan pemberitaan dan informasi yang beredar di media massa baik cetak maupun online, baik media nasional maupun lokal. Pemantauan isu juga dilakukan dengan mengamati opini publik di media sosial maupun berbagai forum diskusi online lainnya.

Semen Indonesia telah menyusun strategi komunikasi dalam pengelolaan isu pembangunan pabrik semen di Rembang. Strategi tersebut dapat dibagi dalam beberapa elemen, meliputi pesan yang disampaikan, pemetaan sasaran komunikasi, media komunikasi yang digunakan, dan melakukan evaluasi terhadap dampak yang diperoleh dari strategi komunikasi yang telah dilakukan.

Strategi komunikasi telah diimplementasikan sesuai dengan jadwal yang direncanakan. Pada akhirnya, Semen Indonesia mampu melakukan perimbangan isu baik di media massa maupun menciptakan tagar yang menjadi trending topic di media sosial, baik itu Facebook maupun Twitter. Hal ini menunjukkan bahwa Semen Indonesia telah mampu meminimalisirkan isu negatif terkait Pabrik Rembang yang dapat mengancam citra dan reputasi perusahaan.

Dalam melakukan pengelolaan isu, Tim Komunikasi Perusahaan Semen Indonesia melakukan penyampaian informasi yang sesuai antara data dan fakta yang ada. Pembuatan konten komunikasi difokuskan pada perkembangan proyek, progres kasus hukum, program pemberdayaan masyarakat, dan dukungan yang diterima dari berbagai pemangku kepentingan. Selain itu, Semen Indonesia aktif menyajikan data dan fakta operasional Pabrik Semen Indonesia yang lain. Perusahaan juga memberikan akses yang terbuka kepada media maupun masyarakat yang 
ingin melakukan study banding ke area operasionalnya.

Untuk menjangkau seluruh pemangku kepentingan yang luas, Tim Komunikasi Krisis Semen Indonesia menggunakan berbagai media komunikasi yang ada. Selain melalui akun resmi perusahaan, Semen Indonesia juga melakukan agenda setting dengan berbagai media. Semen Indonesia juga aktif menggelar maupun mengikuti berbagai forum diskusi tentang Pabrik Rembang.

Tim komunikasi melakukan evaluasi secara periodik untuk mengetahui efektifitas strategi komunikasi yang dilakukan. Selain berdasarkan monitoring isu di media massa dan media sosial, penyesuaian strategi dilakukan dengan menganalisa perkembangan aksi dan agenda setting yang dilakukan oleh pihak kontra. Selain itu, Semen Indonesia juga aktif berkomunikasi dan meminta masukan dari Gubernur Jawa Tengah sebagai pemangku kepentingan utama.

\section{DAFTAR PUSTAKA}

Coombs, W. T., and Holladay, S. J. (2010). The Handbook of Crisis Communication. Singapore: Wiley-Blackwell.

Fink, Steven. (2000). Crisis Management: Planning fot The Inevitable. Lincoln: American Management Assocation.

Heath, R. L. and Coombs, W. T. (2006). Today's Public Relations: An Introduction. California: Sage Publications.

Kriyantono, R. (2012). Teknik Praktis Riset Komunikasi: Disertasi Contoh Praktis Riset Media, Public Relations, Advertising, Komunikasi Organisasi, Komunikasi Pemasaran. Jakarta: Kencana Media Group.

Kriyantono, R. (2015). Public Relations, Issue \& Crisis Management: Pendekatan Critical Public Relations, Etnografi Kritis \& Kualitatif. Jakarta: Prenadamedia Group.
Pembayun. (2013). One Stop: Qualitative Research Methodology in Communication. Jakarta: Penerbit Lentera Ilmu Cendekia.

Regester, M. and Larkin, J. (2002). Risk Issues and Crisis Management: A Case Book of Best Practice Third Edition. London: Chartered Institute of Public Relations.

Rogers, E. M. (1997). A History of Communication Study: A Biographical Approach. New York: The Free Press.

\section{Artikel dari website dengan nama penulis}

Saturi, Sapariah. (2014, August 8). Soal Amdal Tambang Semen di Rembang, Ini Kata Pakar Hukum Lingkungan. Diakses dari https://www.mongabay.co.id/2014/08/08/soalamdal-tambang-semen-di-rembang-ini-katapakar-hukum-lingkungan/

\section{Jurnal cetak}

Benoit, W. L. (1995). Image repair discourse and crisis communication. Public Relations Review, 23 (2), pp.177-187.

Cockerill, K. (2002). Context Is Key: The Media Role in Shaping Public fortunatPerceptions about Environmental Issues. Journal of Environmental Practice 4(2): 107-113.

Foux, G. (2006). Consumer-generated media: Get your customers involver. Brand Strategy. pp.38-39.

Mithcell, R., Agle, B.R., and Wood, D.J. (1997). Toward a Theory of Stakeholder Identification and Salience: Defining the Principle of Who and What Really Counts. The Academy of Management Review Vol. 22.

\section{Surat Kabar Online}

Rofiuddin. (2014, September 1). Izin Proyek Pabrik Semen di Rembang Digugat. Tempo.co. Diakses dari https://nasional.tempo.co

Rofiuddin. (2016, November 3 ). Dua Penentang Pabrik Semen Rembang Dilaporkan. Tempo.co. Diakses dari https://nasional.tempo.co

Safuan, A. (2017, 7 Mei). Embung-Embung Itu Sejahterakan Warga Rembang. Media Indonesia. Diperoleh dari: https://mediaindonesia.com/

Tolak pembangunan pabrik semen, sembilan perempuan cor kaki. (2016, April 13). BBC Indonesia. Diperoleh dari https://www.bbc.com 
